\title{
Analysis of Interconnected Hydro-Pneumatic Suspension System for Load Sharing among Heavy Vehicle Axles
}

\author{
Ferhat Saglam $^{1}$, Y. Samim Unlusoy ${ }^{2}$ \\ ${ }^{1}$ Middle East Technical University, Mechanical Engineering Department/ASELSAN Inc., Ankara, Turkey \\ fesaglam@gmail.com \\ ${ }^{2}$ Middle East Technical University, Mechanical Engineering Department \\ Ankara, Turkey \\ unlusoy@metu.edu.tr
}

\begin{abstract}
The aim of this study is the modelling and analysis of a Hydro-Pneumatic (HP) suspension system interconnected for load sharing in heavy vehicles. The aim of the interconnected HP suspension system is to equalize the load of the suspension units of the axles in axle group(s) of multi-axle heavy vehicles. For the heavy vehicle systems with three and more axles, equalization of the suspension forces of the axle group(s) is a necessity to protect both the road and the vehicle. A single vehicle unit with three and more axles forms a statically indeterminate problem and the loads carried by each axle depend on the deformation of the axles and the suspension travel. For certain road inputs, some axle loads may become excessive. In this study, the nonlinear mathematical model of a heavy vehicle with interconnected load sharing HP suspension system is derived and the linearized version of the nonlinear model is obtained. Transfer functions of the vehicle system are obtained for frequency response analyses to assess the performance and to carry out a parametric analysis. Simulations are performed using speed bump input and random road inputs. A parametric study is performed to examine the effects of the conductor size connecting the HP suspension units on the load sharing performance.
\end{abstract}

Keywords: Hydro-Pneumatic Suspension, Load Sharing, Interconnected Suspension, Heavy Vehicles

\section{Introduction}

In the literature, most of the studies on the interconnected HP suspension systems are carried out in terms of their roll and pitch stiffness characteristics. When the suspension units are connected to each other in the so called $\mathrm{X}$ arrangement in roll plane, pitch plane, or full vehicle model; their stiffness and damping characteristics can be increased in these directions [1-3]. These characteristics of the interconnected HP suspension systems are used to improve the braking/accelerating and handling characteristics of the vehicle model [4-5].

One of the important design requirements in heavy vehicle suspension systems is the equalization of axle loads in axle groups [6]. In the literature, there are a limited number of studies about the load sharing suspension systems. In the study of the Potter et al. [7], dynamic axle forces of heavy vehicles measured on road tests are presented. They have concluded that axle groups with air suspensions have better static load sharing than axle groups with mechanical (steel) suspensions. Moreover, they have stated that tandem axles with air suspension have better low frequency (body bounce) axle force correlation and those with independent suspensions have better high frequency (wheel hop) axle force correlation. Chen et al. [8] have presented the model of a tri-axle semi-trailer with interconnected air suspensions and analyses of the effects of suspension parameters on dynamic load-sharing performance of the semi-trailer. Chen et al. [9] have extended the previous study including the effects of the driving conditions and the suspension parameters on the dynamic load sharing performance of the three-axle semi-trailer. However, the load sharing characteristics of the interconnected HP suspension systems for heavy vehicles have not been studied to any extend.

The objective of this study is the investigation of the load sharing characteristics of a proposed interconnection configuration for a three-axle heavy vehicle equipped with HP suspensions. For this purpose, the mathematical model of the interconnected HP suspension system has been derived. Linearized state space model of the nonlinear model has been derived to examine the general characteristics of the proposed interconnected HP suspension system in an analytical manner. A parametric study has also been performed in the frequency domain to examine the dynamic axle force performance of the 
load sharing interconnected HP suspension system. Simulations are performed to examine the static and dynamic load sharing performance of the interconnected HP suspension for different driving conditions.

\section{Modelling of the Heavy Vehicle with Load Sharing Interconnected HP Suspension System}

The heavy commercial vehicle on which the load sharing interconnected HP suspension system is mounted is shown in figure 1 and the parameters of the vehicle are listed in table 1.

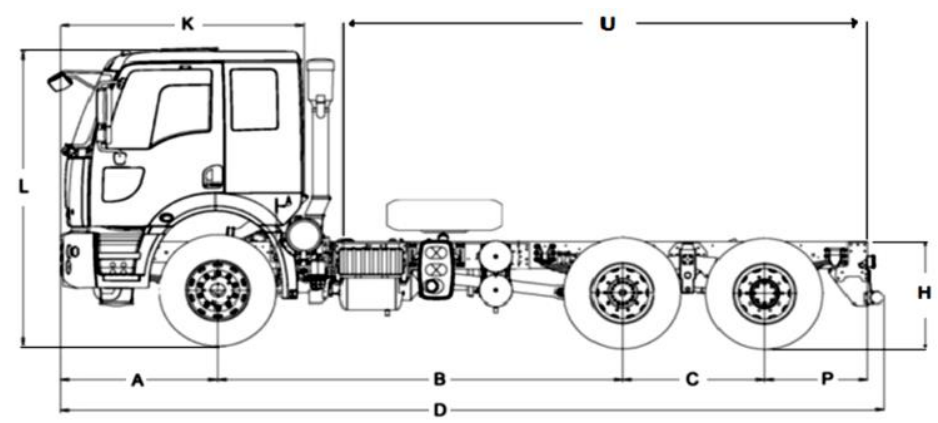

Fig. 1: Three-axle heavy commercial vehicle [10].

Table 1. Vehicle parameters.

\begin{tabular}{|l|c|c|}
\hline \multicolumn{1}{|c|}{ Parameter Definition } & Symbol & Value \\
\hline Distance between the Front and Intermediate Axles & $\mathrm{B}$ & $3.8 \mathrm{~m}$ \\
\hline Distance between the Intermediate and Rear Axles & $\mathrm{C}$ & $1.305 \mathrm{~m}$ \\
\hline Loaded Total Mass & $\mathrm{M}$ & $25000 \mathrm{~kg}$ \\
\hline Pitch Moment of Inertia & $\mathrm{I}$ & $62000 \mathrm{kgm}$ \\
\hline Front Axle Load Capacity & $\mathrm{M}_{\mathrm{F}}$ & $7000 \mathrm{~kg}$ \\
\hline Rear Axle Load Capacity & $\mathrm{M}_{\mathrm{R}}$ & $18000 \mathrm{~kg}$ \\
\hline
\end{tabular}

To be able to equalize the load at the intermediate and rear axle group, an interconnection between the intermediate and rear axle HP suspension oil volumes is intuitively proposed. The schematic of the interconnected HP suspension is shown in figure 2. Front suspension is unconnected and the intermediate and rear suspensions are interconnected to each other by hydraulic conductors. Front suspension system consists of a HP suspension unit which consists of a gas volume, oil volumes, floating piston, damper valve, and hydraulic cylinder and piston. Rear axle suspension unit consists of two HP suspension units connected to each other by hydraulic conductors from oil volumes [11]. In the following sections, the pitch plane model of the vehicle is developed. Thus the term axle is used in the sense of a suspension system belonging to a single side of the vehicle. The aim of the hydraulic conductors is to allow the flow of oil between intermediate and rear suspension units for load equalization.

\subsection{Modelling of Gas Dynamics}

Gas characteristics are derived using polytropic gas equation. Absolute gas pressures $\mathrm{P}_{3 \mathrm{~F}}, \mathrm{P}_{3 \mathrm{M}}$, and $\mathrm{P}_{3 \mathrm{R}}$ are given by the expressions

$$
\begin{aligned}
P_{3 F} & =\frac{P_{30 F} V_{30 F}^{\kappa}}{\left[V_{30 F}+A_{p} z_{f p t F}\right]^{\kappa}} \\
P_{3 M} & =\frac{P_{30 M} V_{30 M}^{\kappa}}{\left[V_{30 M}+A_{p} Z_{f p t M}\right]^{\kappa}} \\
P_{3 R} & =\frac{P_{30 R} V_{30 R}^{\kappa}}{\left[V_{30 R}+A_{p} Z_{f p t R}\right]^{\kappa}}
\end{aligned}
$$




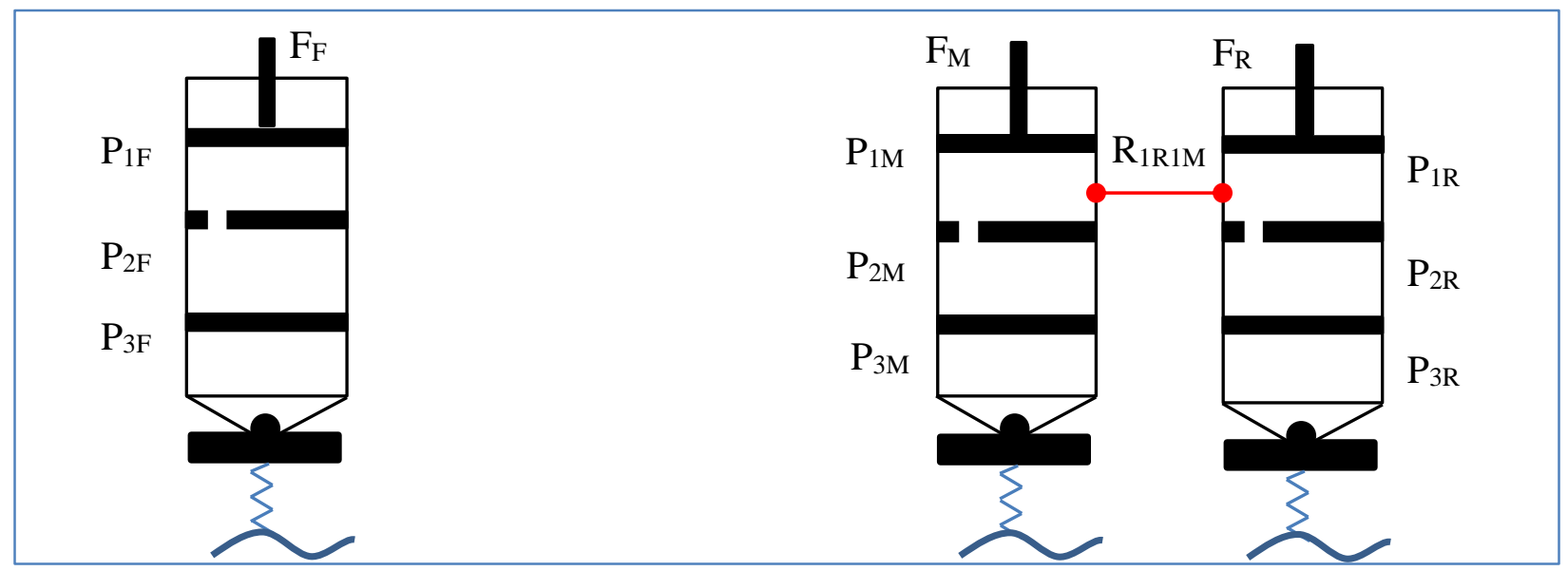

Fig. 2: Interconnected load-sharing HP suspension system for a heavy vehicle.

where $\mathrm{V}_{30 \mathrm{~F}}, \mathrm{~V}_{30 \mathrm{M}}$, and $\mathrm{V}_{30 \mathrm{R}}$ and $\mathrm{P}_{30 \mathrm{~F}}, \mathrm{P}_{30 \mathrm{M}}$, and $\mathrm{P}_{30 \mathrm{R}}$ are gas volumes and absolute gas pressures at static equilibrium for front, intermediate, and rear suspension units respectively, $\mathrm{Z}_{\mathrm{fptF}}, \mathrm{Z}_{\mathrm{fptM}}$, and $\mathrm{Z}_{\mathrm{fptR}}$ are the relative displacement of the front, intermediate, and the rear floating pistons with respect to wheel hub displacements, respectively, $A_{p}$ is the piston area, and $\kappa$ is the polytropic gas coefficient.

\subsection{Modelling of Floating Piston Dynamics}

Equations of motion for the floating pistons are given by

$$
\begin{gathered}
\left(P_{3 F}-P_{A t m}\right) A_{p}-P_{2 F} A_{p}-F_{f p f F}-M_{f p} g=M_{f p} \ddot{z}_{f p F} \\
\left(P_{3 M}-P_{A t m}\right) A_{p}-P_{2 M} A_{p}-F_{f p f M}-M_{f p} g=M_{f p} \ddot{z}_{f p M} \\
\left(P_{3 R}-P_{A t m}\right) A_{p}-P_{2 R} A_{p}-F_{f p f R}-M_{f p} g=M_{f p} \ddot{z}_{f p R}
\end{gathered}
$$

where $\mathrm{P}_{\mathrm{Atm}}$ is the atmospheric pressure, $\mathrm{P}_{2 \mathrm{~F}}, \mathrm{P}_{2 \mathrm{M}}$, and $\mathrm{P}_{2 \mathrm{R}}$ are the oil pressures in the second oil volumes of front, intermediate, and rear suspension units respectively, $\mathrm{F}_{\mathrm{fpfF}}, \mathrm{F}_{\mathrm{fpfM}}$, and $\mathrm{F}_{\mathrm{fpfR}}$ are the Coulomb friction between the cylinder wall and floating piston for front, intermediate, and rear suspension units respectively, $\mathbf{M}_{\mathrm{fp}}$ is the floating piston mass, $g$ is the gravitational acceleration, and $\mathrm{z}_{\mathrm{fpF}}, \mathrm{z}_{\mathrm{fpM}}$, and $\mathrm{z}_{\mathrm{fpR}}$ are the front, intermediate, and rear floating piston displacement, respectively.

\subsection{Modelling of Orifice and Continuity Equations}

Flow of the oil through the orifices can be written by using the orifice and continuity equations as,

$$
\begin{gathered}
Q_{2 F 1 F}=A_{v} C_{D} \sqrt{\frac{2}{\rho}\left|P_{2 F}-P_{1 F}\right| \operatorname{sign}\left(P_{2 F}-P_{1 F}\right)=A_{p}\left(\dot{z}_{p F}-\dot{z}_{t F}\right)} \\
Q_{2 M 1 M}=A_{v} C_{D} \sqrt{\frac{2}{\rho}\left|P_{2 M}-P_{1 M}\right| \operatorname{sign}\left(P_{2 M}-P_{1 M}\right)=A_{p}\left(\dot{z}_{p M}-\dot{z}_{t M}\right)-Q_{1 R 1 M}} \\
Q_{2 R 1 R}=A_{v} C_{D} \sqrt{\frac{2}{\rho}\left|P_{2 R}-P_{1 R}\right| \operatorname{sign}\left(P_{2 R}-P_{1 R}\right)=A_{p}\left(\dot{z}_{p R}-\dot{z}_{t R}\right)+Q_{1 R 1 M}}
\end{gathered}
$$

where $\mathrm{Q}_{2 \mathrm{FIF}}, \mathrm{Q}_{2 \mathrm{M} 1 \mathrm{M}}$, and $\mathrm{Q}_{2 \mathrm{R} 1 \mathrm{R}}$ are the oil flow rates passing through the orifices of front, intermediate, and rear suspension units, respectively, $A_{v}$ is the orifice opening area, $C_{D}$ is the orifice loss factor, $\rho$ is the oil density, and $P_{1 F}, P_{1 M}$, and $\mathrm{P}_{1 \mathrm{R}}$ are the oil pressures in the first oil volumes of front, intermediate, and rear suspension units, respectively, $\mathrm{Z}_{\mathrm{pF}}, \mathrm{Z}_{\mathrm{pM}}$, 
and $\mathrm{z}_{\mathrm{pR}}$ are the front, intermediate, and rear piston displacement respectively, and $\mathrm{z}_{\mathrm{tF}}, \mathrm{z}_{\mathrm{tM}}$, and $\mathrm{z}_{\mathrm{tR}}$ are the front, intermediate, and rear wheel hub displacement respectively.

\subsection{Modelling of Hydraulic Conductors}

Oil flow rate though the hydraulic conductor, $\mathrm{Q}_{1 \mathrm{R} 1 \mathrm{M}}$, which connects the first oil volumes of intermediate and rear suspension units in rear axle group can be written as,

$$
Q_{1 R 1 M}=R\left(P_{1 R}-P_{1 M}\right)=\frac{\pi D^{4}}{128 \mu L}\left(P_{1 R}-P_{1 M}\right)
$$

where $\mathrm{R}$ is the hydraulic conductor resistance, $\mathrm{D}$ is the conductor diameter, $\mu$ is the dynamic oil viscosity, and $\mathrm{L}$ is the conductor length. Using these elementary equations, suspension forces can be derived.

\subsection{Suspension Forces and Equation of Motions}

Front, intermediate, and the rear suspension forces, $\mathrm{F}_{\mathrm{F}}, \mathrm{F}_{\mathrm{M}}$, and $\mathrm{F}_{\mathrm{R}}$ can be written as,

$$
\begin{aligned}
F_{F} & =P_{1 F} A_{p}-F_{p f F} \\
F_{M} & =P_{1 M} A_{p}-F_{p f M} \\
F_{R} & =P_{1 R} A_{p}-F_{p f R}
\end{aligned}
$$

where $\mathrm{F}_{\mathrm{pfF}}, \mathrm{F}_{\mathrm{pfM}}$, and $\mathrm{F}_{\mathrm{pfR}}$ are the Coulomb friction force between cylinder wall and piston for front, intermediate, and rear suspension units, respectively. Further one can write equation of motions as

$$
\begin{aligned}
F_{F}+F_{M}+F_{R}-M g & =M \ddot{z} \\
-a F_{F}+b F_{M}+c F_{R} & =I \ddot{\theta}
\end{aligned}
$$

where $\mathrm{M}$ is the sprung mass, $\mathrm{a}$ is the distance between front axle and centre of gravity, $\mathrm{b}$ is the distance between the intermediate axle and centre of gravity, $\mathrm{c}$ is the distance between the rear axle and the centre of gravity, I is the pitch moment of inertia, $\mathrm{z}$ is the sprung mass vertical displacement, and $\theta$ is the sprung mass pitch angle. In order to examine the frequency response characteristics of the interconnected and the unconnected HP suspension system for the heavy vehicle, gas and damper valve dynamics are linearized. Assuming negligible floating piston dynamics and negligible friction forces, transfer functions between the road displacement inputs and axle forces will then be obtained as,

$$
\left\{\begin{array}{l}
T F_{F}(s) \\
T F_{M}(s) \\
T F_{R}(s)
\end{array}\right\}=\left[\begin{array}{lll}
G_{11}(s) & G_{12}(s) & G_{13}(s) \\
G_{21}(s) & G_{22}(s) & G_{23}(s) \\
G_{31}(s) & G_{32}(s) & G_{33}(s)
\end{array}\right]\left\{\begin{array}{c}
z_{0 F}(s) \\
z_{0 M}(s) \\
z_{0 R}(s)
\end{array}\right\}
$$

where $\mathrm{TF}_{\mathrm{F}}, \mathrm{TF}_{\mathrm{M}}$, and $\mathrm{TF}_{\mathrm{R}}$ are the front, intermediate, and the rear axle forces, respectively; $\mathrm{z}_{0 \mathrm{~F}}, \mathrm{z}_{0 \mathrm{M}}$, and $\mathrm{z}_{0 \mathrm{R}}$ are the front, intermediate, and rear road displacement inputs, respectively; and G's are the corresponding transfer function between axle forces and road displacement inputs.

\section{Simulations}

In the study of Davis and Bunker [6], the definition of dynamic load sharing is given as "Dynamic load sharing can be defined as a measure of the ability of a heavy vehicle multi-axle group to equalize load across its wheels under typical travel conditions i.e. in the dynamics sense at typical travel speed and operating conditions of that vehicle". This definition is adopted in the current study. Dynamic load sharing performance of the suspension systems is analysed by using the dynamic load sharing coefficient, DLSC [12] also cited and used in the references $[6,8]$. 


$$
D L S C=\sqrt{\frac{\sum_{j=1}^{k}\left(D L S_{i}(j)-\overline{D L S_{i}}\right)^{2}}{k}}
$$

In Eq. (17), $\mathrm{k}$ is the total number of data points. DLS is the dynamic load sharing defined as

$$
D L S_{i}(j)=\frac{n F_{i}(j)}{\sum_{i=1}^{n} F_{i}(j)}
$$

where $\mathrm{F}_{\mathrm{i}}$ is the axle force at $\mathrm{i}^{\text {th }}$ axle and $\mathrm{n}$ is the number axles in an axle group.

In order to examine the static load sharing performance of the interconnected HP suspension system, simulations with a speed bump road input are performed. Similarly, in order to examine the dynamic load sharing performance of the HP suspension system, simulations with random road displacement input are carried out. Frequency response functions (FRFs) between axle loads and the road inputs for rear axle group interconnected suspension unit for different hydraulic conductor diameters are shown in figure 3.
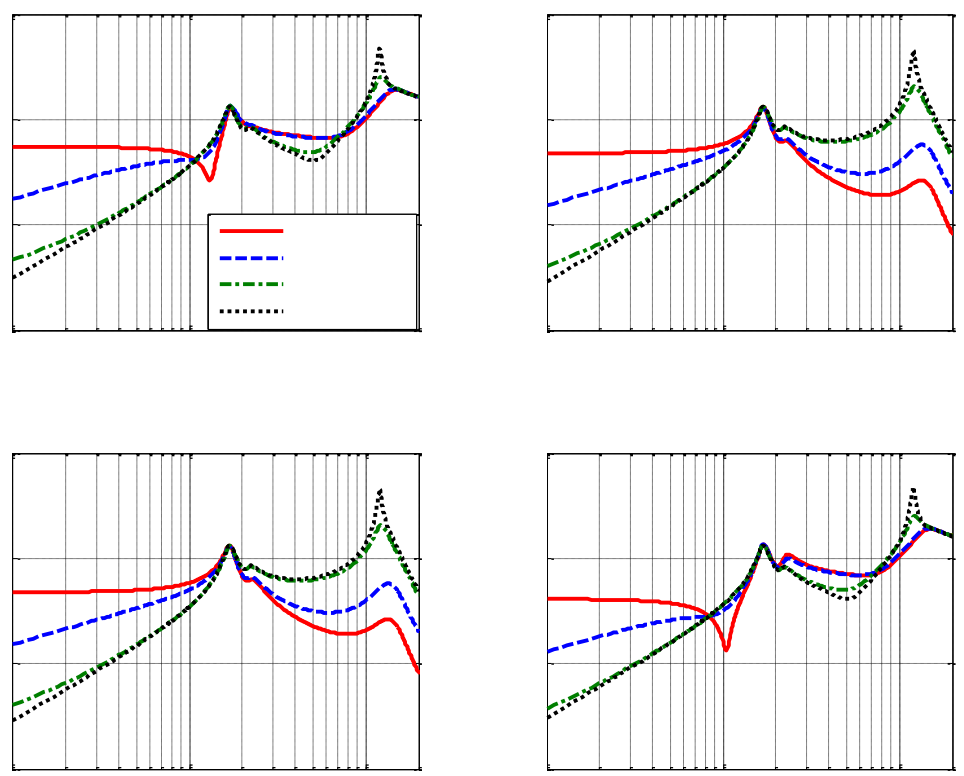

Fig. 3: Dynamic tire force FRFs.

When the transfer functions $\mathrm{G}_{22}$ and $\mathrm{G}_{33}$ in figure 3 are examined, it is seen that, at low frequencies below the body bounce frequency, interconnected HP suspension system has lower FRFs than the FRFs of the axle group with unconnected HP suspension systems. This means that when one of the axles of rear axle group is excited by the road displacement input, the total load carried by the intermediate and rear axle is shared almost equally. Moreover, at frequencies between body bounce and wheel hop, again interconnected HP suspension system has lower axle forces. However, around wheel hop frequency, rear axle group with the unconnected HP suspension system has lower axle forces. As will be shown with the simulations performed with the random road displacement inputs, a rise in the FRFs around wheel hop frequency result in an increase in the dynamic axle load. $G_{23}$ shows the dynamic axle load of intermediate suspension due to road displacement input on the rear axle. At frequencies lower than the body bounce frequency, interconnected suspension system provides lower interaction between the intermediate and rear axles. However at frequencies higher than the body bounce frequency, unconnected HP suspension system provides lower axle force response. This means that, unconnected HP suspension system results in a lower interaction between axles and suspensions of rear axle group. 
From figure 3, effect of the hydraulic conductor diameter on the load sharing characteristics of the HP suspension system can be observed. When the conductor diameter is decreased, characteristics of the interconnected HP suspension system have a tendency to approach the characteristics of the unconnected HP suspension system. Further, diameter of the interconnecting hydraulic conductor has a strong influence on the performance of the interconnected HP suspension system.

After the FRFs of the interconnected and unconnected HP suspension systems are examined, now load sharing performances are to be examined by time domain simulations. Figure 4 to 7 show the axle forces obtained from the simulation by the speed bump road displacement input when the vehicle is travelling at $5 \mathrm{~km} / \mathrm{h}$.
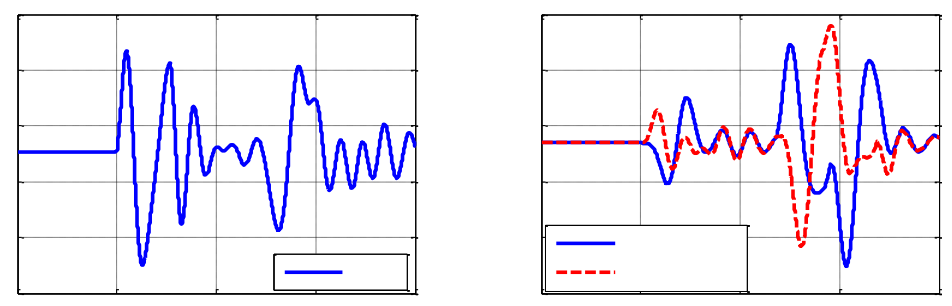

Fig. 4: Axle forces for interconnected suspension with conductor diameter, $\mathrm{D}=0.01 \mathrm{~m}$.
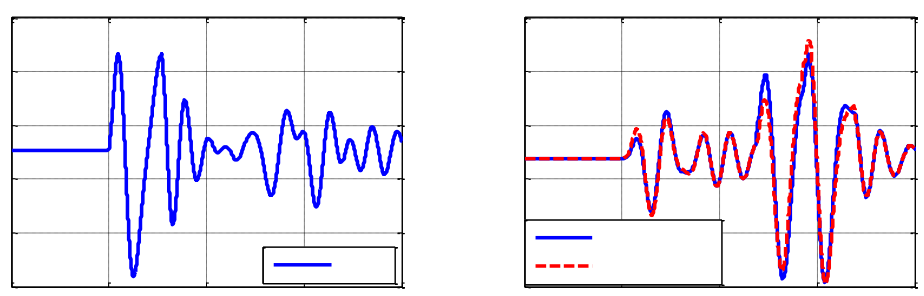

Fig. 5: Axle forces for interconnected suspension with conductor diameter, $\mathrm{D}=0.02 \mathrm{~m}$.
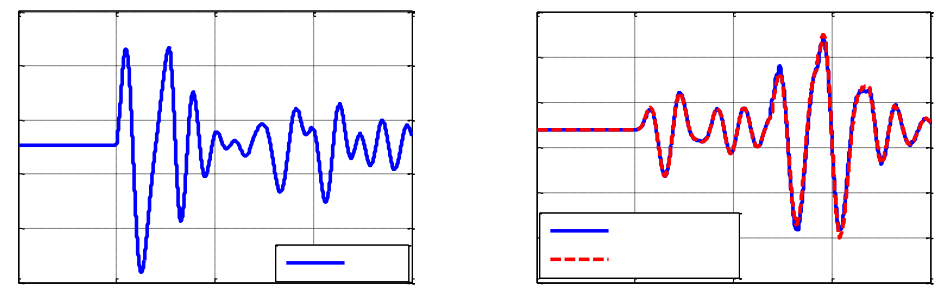

Fig. 6: Axle forces for interconnected suspension with conductor diameter, $\mathrm{D}=0.03 \mathrm{~m}$.
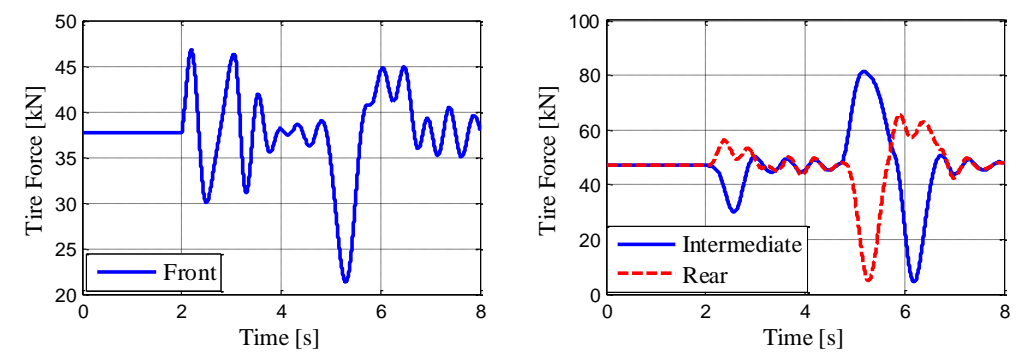

Fig. 7: Axle forces for unconnected suspension.

As can be seen from figure 6, in which the conductor diameter is $0.03 \mathrm{~m}$, intermediate and rear axle forces are almost equal to each other. However, when the conductor diameter is reduced to $0.01 \mathrm{~m}$, intermediate and rear axle forces are different from each other. For the vehicle with unconnected suspension system, when the vehicle goes over a bump, the intermediate axle forces increase first, and then the rear axle forces increase. However for a vehicle with interconnected HP 
suspension system with larger conductor diameter, the intermediate and rear axle forces increase and decrease simultaneously due to static load sharing characteristics of the suspension system. Maximum values of the suspension forces are given in table 2. As can be seen from table 2, intermediate axle force increases excessively when the vehicle goes over a speed bump in the case of the unconnected HP suspension system.

Table 2: Maximum values of axle forces.

\begin{tabular}{|c|c|c|c|c|}
\hline & \multicolumn{4}{|c|}{ Maximum axle force [kN] } \\
\hline & \multicolumn{3}{|c|}{ Interconnected } & \multirow{2}{*}{ Unconnected } \\
\hline Axle & $\mathrm{D}=\mathbf{0 . 0 1}[\mathrm{m}]$ & $\mathrm{D}=\mathbf{0 . 0 2}[\mathrm{m}]$ & $\mathrm{D}=\mathbf{0 . 0 3}[\mathrm{m}]$ & \\
\hline Front & 46.7 & 46.6 & 46.7 & 46.8 \\
\hline Intermediate & 64.6 & 56.7 & 57.2 & 81.4 \\
\hline Rear & 68.0 & 57.9 & 57.4 & 65.7 \\
\hline
\end{tabular}

After the static load sharing performance of the HP suspension systems are examined, now the dynamic load sharing performance are to be examined. For this purpose, simulations with random road inputs at different longitudinal speeds are performed. DLSCs for interconnected suspension with different conductor diameters and for unconnected suspension calculated at different vehicle longitudinal speeds are presented in table 3.

Table 3: DLSC for different suspensions and vehicle speeds.

\begin{tabular}{|c|c|c|c|c|c|}
\hline & & \multicolumn{3}{|c|}{ Interconnected } & \multirow{2}{*}{ Unconnected } \\
\hline & $\mathbf{V}[\mathbf{k m} / \mathbf{h}]$ & $\mathbf{D = 0 . 0 1}[\mathbf{m}]$ & $\mathbf{D = 0 . 0 2}[\mathbf{m}]$ & $\mathbf{D = 0 . 0 3}[\mathbf{m}]$ & \\
\hline & $\mathbf{6 0}$ & 1.36 & 1.38 & 1.92 & 1.60 \\
\cline { 2 - 5 } & $\mathbf{7 0}$ & 1.60 & 2.32 & 4.86 & 1.83 \\
\cline { 2 - 5 } DLSC [\%] & $\mathbf{8 0}$ & 2.06 & 3.41 & 7.47 & 2.28 \\
\cline { 2 - 5 } & $\mathbf{9 0}$ & 2.88 & 4.55 & 9.9 & 3.24 \\
\hline
\end{tabular}

As can be seen from table 3, for the interconnected suspension, when the diameter of the conductor is reduced, DLSC decreases with it. When the diameter of the conductor is increased too much, there is an excessive increase in the DLSC. Moreover, DLSC for unconnected suspension is similar to DLSC for interconnected suspension with smaller conductor diameter. As stated before, when the diameter of the conductor becomes too large, FRFs at wheel hop frequency also becomes higher. This in turn, results in a rise of the DLSC for interconnected HP suspension system with higher conductor diameter.

\section{Conclusion}

In this study, characteristics of a load-sharing interconnected HP suspension system are investigated. It has been observed that at low frequencies, interconnected HP suspension system has better load sharing performance than the unconnected suspension. When the diameter of the hydraulic conductor is increased, the load sharing performance is improved. At frequencies between the body bounce and the wheel hop frequencies, interconnected suspension system gives the best axle force sharing performance. Further, when the diameter of the connecting conductor is increased, the dynamic axle forces decrease. Around wheel hop frequencies, the vehicle with the unconnected suspension shows the best axle force sharing performance. Moreover, for the vehicle with the interconnected HP suspension system, when the diameter of the hydraulic connector is increased, the dynamic axle force sharing performance decreases. The simulation performed with bump road displacement input at low longitudinal speed shows that the interconnected suspension system with the larger conductor diameter has the best results. Unconnected suspension has inferior static load sharing performance. The simulation results from the random road displacement inputs at longitudinal speeds between 60 to $90 \mathrm{~km} / \mathrm{h}$ indicate that the interconnected suspension with some intermediate connector diameter has the best dynamic axle force performance depending on the frequency content of the road input. The unconnected suspension has better performance than the interconnected suspension with higher connector diameters. 
As a result, the proposed interconnected HP suspension system can be used to equalize axle forces of heavy vehicles either for static or dynamic case. Using a hydraulic conductor with larger diameters increases the static load sharing performance. However using a conductor with smaller diameters increases dynamic load sharing performance. Thus, for a compromised static and dynamic load sharing performance, a conductor with a somewhat intermediate diameter should be used. In order to improve the static and dynamic load sharing performance simultaneously, a flow control valve can be placed on the interconnecting hydraulic conductor. A semi-active control can be used to adjust the opening of the conductor according to the driving environment of the vehicle. When the vehicle goes on a good road surface at high speed, the valve opening can be decreased and thus the flow is restricted between connecting ports on the intermediate and rear suspensions.

Similarly, when the vehicle goes over a speed bump at low speeds, the valve opening can be increased to reduce the flow restriction between connecting ports on the intermediate and rear suspensions.

\section{References}

[1] D. Cao, "Theoretical analyses of roll- and pitch-coupled hydro-pneumatic strut suspensions," Ph.D. dissertation, Mechanical Engineering Department, Concordia University, Canada, 2008.

[2] N. Zhang, W. A. Smith, and J. Jeyakumaran, "Hydraulically interconnected vehicle suspension: background and modeling," Vehicle System Dynamics: International Journal of Vehicle Mechanics and Mobility, vol. 48, no. 1, pp. 1740, 2010.

[3] W. A. Smith, N. Zhang, and J. Jeyakumaran, "Hydraulically interconnected vehicle suspension: theoretical and experimental ride analysis," Vehicle System Dynamics: International Journal of Vehicle Mechanics and Mobility, vol. 48, no. 1, pp. 41-64, 2010.

[4] W. A. Smith, N. Zhang, and W. Hu, "Hydraulically interconnected vehicle suspension: handling performance," Vehicle System Dynamics: International Journal of Vehicle Mechanics and Mobility, vol. 49, no. 1-2, pp. 87-106, 2011.

[5] F. Ding, X. Han, Z. Luo, and N. Zhang, "Modeling and characteristic analysis of tri-axle trucks with hydraulically interconnected suspensions," Vehicle System Dynamics: International Journal of Vehicle Mechanics and Mobility, vol. 50, no. 12, pp. 1877-1904, 2012.

[6] L. E. Davis and J. M. Bunker, "Dynamic load sharing for heavy vehicles: a new metric," Road and Transport Research, vol. 18, no. 4, pp. 23-37, 2009.

[7] T. E. C. Potter, D. Cebon, A. C. Callop, and D. J. Cole, "Road-damaging potential of measured dynamic tyre forces in mixed traffic," in Proc. Instn. Mech. Engrs., vol. 210, pp. 215-225, 1996.

[8] Y. Chen, J. He, M. King, W. Chen, C. Wang, and W. Zhang, "Model development and dynamic load-sharing analysis of longitudinal-connected air suspensions," Strojniški vestnik - Journal of Mechanical Engineering, vol. 59, no. 1, pp. 14-24, 2013.

[9] Y. Chen, J. He, M. King, W. Chen, and W. Zhang, "Effect of driving conditions and suspension parameters on dynamic load-sharing of longitudinal-connected air suspensions," Science China, Technological Sciences, vol. 56, no. 3, pp. 666676, 2013.

[10] (2016, February 09). Heavy Commercial Vehicles Technical Properties. [Online], Available: http://www.ford.com.tr/agir-ticari-araclar/ford-cargo-insaat.

[11] F. Saglam and Y. S. Unlusoy, "Modeling and state dependent Riccati equation control of an active hydro-pneumatic suspension system," in Proceedings of the International Conference of Control, Dynamic Systems, and Robotics, no. 31, Ottawa, Ontario, Canada, May 15-16 2014.

[12] J. De Pont, "Assessing heavy vehicle suspensions for road wear," Research Report, no. 95, New Zealand Transport Agency, Wellington, 1997. 